\title{
The Roles of Chemokines in Immune Response to Mycobacterial Infection
}

\author{
Seungwha Paik ${ }^{1,2}$, Miso Yang ${ }^{1,2}$, Hyun-Woo Suh ${ }^{1,2}$, Eun-Kyeong Jo ${ }^{1,2 *}$ \\ ${ }^{1}$ Department of Microbiology, Chungnam National University School of Medicine, Daejeon 35015, Republic of Korea \\ ${ }^{2}$ Infection Control Convergence Research Center, Chungnam National University School of Medicine, Daejeon 35015, \\ Republic of Korea
}

\author{
Corresponding \\ Eun-Kyeong Jo, Professor \\ Department of Microbiology, and \\ Infection Control Convergence Research \\ Center, Chungnam National University \\ School of Medicine, 266 Munhwa-ro, \\ Jung-gu, Daejeon 35015, Republic of \\ Korea \\ Phone : $+82-42-580-8243$ \\ Fax : $+82-42-585-3686$ \\ E-mail : hayoungj@cnu.ac.kr
}

Received : November 18, 2020

Revised : December 10, 2020

Accepted : December 14, 2020

No potential conflict of interest relevant to this article was reported.

Copyright (C) 2020 Journal of Bacteriology and Virology

(C) This is an Open Access article distributed under the terms of the Creative Commons Attribution Non-Commercial License

(http://creativecommons.org/

license/by-nc/3.0/).
Tuberculosis (TB), a global and deadly infectious disease caused by Mycobacterium tuberculosis (Mtb), is manifested with host immune reaction. The balanced regulation between protective immune and pathologic inflammatory responses is critical to control progression to TB. Chemokines are a large family of cytokines that play an essential role for chemotaxis of immune and inflammatory cells to the sites of infection. Numerous chemokines including CXCL10 were reported as potential biomarkers of various stages of TB infection. In addition, several chemokines and their receptors play as key players to coordinate host immune defense as innate effectors and mediators of adaptive immune responses. Accumulating evidence suggests that some chemokines, if uncontrolled, are associated with host pathological inflammation during infection. In this review, we will discuss recent advances in understanding which chemokines have potentials as diagnostic markers. In addition, we focus the roles and mechanisms by which chemokines and their receptors are involved in both host immune protection and pathology during TB infection. The controlled activation of chemokine system will determine the coordinated biological outcomes of innate immune responses during pathogenic infection.

Key Words: Tuberculosis, Chemokine, Biomarker, Immune response, Inflammation

\section{INTRODUCTION}

Tuberculosis (TB), an infectious disease caused by Mycobacterium tuberculosis (Mtb), remains global health problem with high morbidity and mortality (https://www. who.int/tb/publications/global-framework-research/en/) (1). Governing TB infection, challenges stagnantly encounters an emerging issue of drug-resistant strains, development of new therapeutics, an urgent need for intervention of latent TB infection (LTBI), a lack of prominent biomarkers for diagnosis, and etc (2-5). Chemokines and their receptors are crucial in the orchestration of the recruitment of phagocytes and immune cells to the sites of infection, affecting inflammatory and wound healing responses and involved in the cell differentiation, proliferation, and innate immunity (6). Indeed, a variety of cells produce chemokines to participate in the innate immune responses, through functional regulation in autocrine, paracrine, and systemic manners (7). During TB infection, chemokines play a variety of functions in mediating innate immunity, inflammation, angiogenesis, cell proliferation and migration, and etc (8-10). In particular, innate cytokine/chemokine pathways play 
critical roles in controlling initial infection and in promoting adaptive immune responses (11). However, the balanced activation between pro- and anti-inflammatory cytokines/chemokines is crucial for mounting effective host resistance against Mtb infection $(8,11)$.

Characterizing the chemokine profiles in TB infections will facilitate the application of specific chemokines and their receptors in early diagnosis of TB. In this review, the features of chemokine profiles and its benefits as potential biomarkers in various stages of pulmonary and extrapulmonary TB and the chemokines that interfere during Mtb infection in both host defense and pathologic inflammation will be described.

\section{OVERVIEW OF INFECTION AND IMMUNITY OF TB}

Although global incidence of TB has been marginally declined, TB infection with multidrug resistant (MDR-TB) and extensively drug resistant strains (XDR-TB) has emerged as a growing public burden in worldwide $(2,12)$. In addition, 1.7 billion world's population (about one fourth of global population) has latent tuberculosis infection (LTBI) due to persistent immune response of Mtb infection deprived of clinical symptom of active TB (https://www.who.int/tb/publications/ global_report/en/). Importantly, a small proportion (about 5-10\%) of LTBI can be reactivated and progress to develop active TB disease throughout lifetime (5). Thus it is urgently needed that new paradigm of treatment strategies for drug-resistant cases and an evaluation tool for the prediction of TB progression during LTBI.

A large body of evidence indicates that the immune system is critical for protection against Mtb infection although the whole feature of protective immunity has not been fully understood (13-15). The immune suppressive status, i.e., a decrease of CD4 count, in the patients with HIV infection increases the reactivation risk of TB infection $(14,16)$. In addition, the treatment of human immunodeficiency virus (HIV)/TB co-infection often develop complex drug interactions and TB-induced immunopathology, such as immune reconstitution inflammatory syndrome $(14,17,18)$. Moreover, granuloma formation in TB infection is a long-term immune reaction to Mtb antigens and host lipids and acts as a double-edged sword to limit infection at the local sites and also to develop inflammation and tissue destruction in the lungs $(11,19,20)$. Understanding the detailed mechanisms for host-pathogen interaction during TB offers an opportunity to develop new strategies against Mtb infection.

Mtb is usually transmitted through inhalation of aerosolized droplets to the lungs, however, Mtb infection is not limited to the lung tissues, and can be occurred in any sites of human body $(21,22)$. Extrapulmonary TB infections include tuberculous pleural effusion (TPE) (23), tuberculous meningitis (22), abdominal TB (24), genitourinary TB (25), and etc. Immune reaction induced by CD4(+) helper type of T lymphocytes are dominant in TPE (26), and tuberculous meningitis is a very severe form of extrapulmonary TB with poor outcomes (22). The mortality rate of tuberculous meningitis is greatly increased in HIV co-infected patients (22). Another public issue of TB is a lack of biomarkers and/or immune parameters that can be useful for early diagnosis in TB and for differential diagnosis for latent TB infection $(3,4)$. In this Review, we highlight the chemokines as potential biomarkers in various stages/types of $\mathrm{TB}$, and additional important functions as effectors in protective immune and inflammatory responses during TB infection.

\section{OVERVIEW OF CHEMOKINES DURING TB INFECTION}

Chemokines and their receptors are expressed by a variety of cells and participate in numerous physiological and pathological functions. In terms of infection and immunity, chemokines play essential roles in hematopoiesis, lymphocyte development, dendritic cell maturation, and etc. (27). Indeed, a variety of chemokines are critically required for innate immune activation for further activation of adaptive immune responses (27). 
According to their numbers and location of the first two cysteine residues, chemokines can be divided into four main subfamilies: CC, CXC, C, and CX3C in the N-terminal region (28). Chemokines bind and transduce signals through G-protein coupled receptors, which possess seven transmembrane regions, i.e., CC (CCR), CXC (CXCR), C (XCR1), and for CX3C (CX3CR1). Upon binding of chemokine receptors with chemokines, they are internalized onto endosomes for further trafficking into a recycling or degradative pathway (29). In addition, chemokine engagement among chemokine receptors triggers the G-protein coupled receptors, subjected to GTP binding to the Ga subunit, resulting in the activation of various signaling pathways, such as PI3K, MAPK, and Rho kinase. These signaling pathways and the related signaling cascade are critically involved in the cell proliferation, inflammation, migration, motility, and immune responses (30-32).

Granuloma is one of the most significant hallmarks of pathological findings of TB, consequently from the early host immune response and appears imperative in the limitation of Mtb infection to prevent upcoming dissemination (33). The mechanisms of the granuloma formation is very complicated and activated by innate and acquired immune responses that embrace numerous immune cells and cytokines/chemokines $(11,20)$. During this process, tumor necrosis factor (TNF) is essentially required for the maintenance of granulomas through induction of $C C$ and $C X C$ chemokines and the recruitment of macrophages and CD4(+) T cells to form functional granulomas $(20,34)$. For example, chemokine (C-X-C motif) ligand 8 (CXCL8) is produced by lung epithelial cells through Mtb-mediated nuclear factor (NF)-kB signaling pathways (35) and by lung fibroblasts in TB granulomas (36) for further recruitment of leukocytes and controlling Mtb within granuloma. However, the uncontrolled activation of pro-inflammatory cytokine/chemokine generation leads to immunopathology during infection and will be detrimental to host defense $(8,37)$. In addition, distinct type of chemokine(s) may participate in the proliferation and activation of protective adaptive immune responses during TB infection (38). Particularly, CCR7, a major chemokine-chemokine receptor in the activation of memory $T$ cells, contributes in defense pathways to establish acquired resistance against TB infection (38). Understanding how the production and signaling of chemokines are controlled and which kinds of chemokine(s) participate in the protective immune functions is vital to develop novel therapeutics against TB.

\section{ROLES OF CHEMOKINES AS BIOMARKERS DURING TB AND EXTRAPULMONARY TB}

\section{CXCL10/IP-10 as biomarkers during TB infection}

Plasma chemokine levels appear to be important biomarkers for pulmonary TB patients (39). Among those chemokines, many studies suggest its important roles for CXCL10 induced by pathogenic stimuli that induce IFN- $\alpha / \beta$, as a diagnostic marker in TB and IFN- $\gamma$ as well (40). A meta-analysis approached from eighteen studies including 2,836 total participants have been applied to CXCL10 suggesting IP-10 is a potential diagnostic marker for pulmonary TB from non-TB (41). Another systematic review and meta-analysis show that IP-10 displays a potential value for diagnosis of latent TB (42). In line with these studies, IP-10, IL-18BP, IFN- $\gamma$, and IL-37 levels are increased in the sera of active pulmonary TB patients from active tuberculosis (ATB) patients, compared to those from healthy latent TB and healthy controls (HC) (43). A study for diagnostic markers of Mycobacterium bovis (M. bovis) infection among cattle have suggested that chemokines such as CXCL9 and CXCL10 and as well as several acute phase cytokines can be useful as potential diagnostic biomarkers of $M$. bovis infection (44).

Moreover, IP-10 secretion level after stimulation of recombinant mycobacterial antigen proline-glutamate 35 (PE35) and proline-proline-glutamate 68 (PPE68) is significantly higher in TB patients, including pulmonary TB and latent TB, when it was compared with HCs (45). However, there is no significant difference in IP-10 production induced by PE35 and PPE68 between pulmonary TB and latent TB (45). A recent systemic review and meta-analysis showed that IP-10 test is useful alternative immunological modality to detect children TB (46). Although more extended data are still required to confirm whether IP-10 is useful as diagnostic marker for TB, these precedents strongly suggest that IP-10 might be a useful target for both adult and children TB and latent TB diagnosis 


\section{Numerous chemokines can be useful TB markers}

In pulmonary TB, the patients had higher production of numerous chemokines including CCL1, CCL3, CXCL1, CXCL2, CXCL9 and CXCL10, when compared to latent TB and HC. In addition, the increased levels of chemokines significantly correlate with bacterial burdens and disease severity, and its levels are reduced after successful anti-tuberculous chemotherapy (39). Moreover, monocyte morphometric parameters (mean monocyte volume and conductivity) and MCP-1 show significant sensitivity and specificity on order to distinguish active pulmonary TB from latent TB (47). Taken together, although the clinical relevance should be monitored in the large population of the patient groups depending on the clinical status, these data propose that there are several kinds of chemokines that can be useful as promising disease markers of TB,

Low body mass index (LBMI) is known as one of the major risk factors of TB, and associated with systemic levels of tumor necrosis factor (TNF)- $\alpha$ and interleukin (IL)-2. However, it never correlates with other numerous chemokines including CCL2/MCP-1, CCL3/MIP1 $\alpha$, CCL4/MIP-13, and CXCL10/IP-10 (48). In the latent TB treatment, the mRNA levels of CCL4, CXCL10, and CXCL11 were significant after isoniazid (INH) therapy, suggesting the chemokine levels would be the promising potential tools for monitoring latent TB after treatment (49). A meta-analysis of nine studies (2,584 TB patients and 2,265 controls) indicated that CCL5 rs2107538 polymorphism was correlated with the susceptibility of TB susceptibility (recessive model: $\mathrm{OR}=1.45,95 \% \mathrm{Cl}=1.02-2.07$ ), particularly among Caucasians (50). However, well-designed functional studies with extended population are warranted for further validation of the SNP studies (50).

\section{Biomarkers during extrapulmonary TB infection}

A recent study suggests that adenosine deaminase (ADA), interferon (IFN)- $\gamma$, and interleukin (IL)-27 show high diagnostic accuracy in TB pleural effusion; however, the profiles of C-X-C motif chemokine ligand 9 (CXCL9), CXCL11, and CXCL12 need to be further examined to prove their diagnostic values in TB pleural effusion (51). In addition, PD-1-expressing mucosal-associated invariant T (MAIT) cells showed increased levels of both CXCL13 and IL-21, and associated with the disease severity of TB pleurisy in the patients (52). CXCL13 is important for the recruitment of CXCR5+ B cells and Tfh to the lymphoid follicles for T-B cell interactions (53) and recognizes CXCR5, a marker for T follicular helper (Tfh) cells (54). However, the roles for PD-1 ${ }^{\text {high }}$ MAIT cells in terms of CXCL13-mediated pathogenesis or protective immune responses are largely unknown. In other studies with TB pleural effusion patients, CCL27 levels were significantly higher in PE samples from anergic patients with TPE, compared to those in non-anergic TPE and malignant PE $(p<0.001)(55)$.

Furthermore, recent studies for the suspected cases of tuberculous meningitis (TBM) showed that the upregulated cytokine/chemokine profiles including IL-12p40, IL-13, and MIP-1 $\alpha$ as potentially useful adjunctive markers for diagnosis of TBM (56). These data suggest that specific chemokine levels, combined with the known biomarker ADA levels, might be helpful for the diagnosis of extrapulmonary TB. The chemokines as potential biomarkers during TB infection are summarized in Table 1.

\section{PROTECTIVE ROLES OF CHEMOKINES DURING TB INFECTION}

\section{Activation of protective $T$ cells and innate lymphoid cells}

Appropriate induction of innate and adaptive immune responses contributes to the protective immunity against TB. In mouse infection models, multiple chemokine receptors contribute to the recruitment of CXCR3+ Th1 cells into the lung parenchyma in order to control Mtb growth $(57,58)$. A recent study showed an essential protective function of chemokine CXCL13 in the early protective immunity against TB (59). The study showed that circulating innate lymphoid cells (ILC) subsets are depleted systemically in pulmonary TB (PTB) patients, and upregulated after treatment (59). Besides, Mtb 
infection led to an increase of ILC3 in the infected mouse lungs, leading to early alveolar macrophage accumulation and control of Mtb. Importantly, CXCR5/CXCL13 axis is critically involved the migration of ILC3 to induce early protective effects against Mtb and formation of lymphoid follicles within granulomas (59). These data strongly suggest that the CXCR5/CXCL13 is required for the protective immunity against Mtb infection through functional activation of ILC3s during Mtb infection (59). Together, these data suggest that the control of Mtb in vivo is mediated through specific chemokine/chemokine receptor axis via the induction of migration of protective immune cells against Mtb. However, it also proposes that the interaction of chemokines and their chemokine receptors on Th1 cells specifically activated by mycobacterial antigens plays a dispensable role in the migration of protective CD4+ T cells into the infected lungs (60). Indeed, there are many other exceptions in chemokine activity to induce protective responses, discussed in the following.

Interestingly, the nicotine inhibits the secretion of several chemokines including CXCL9 and CXCL10 in Mtb-infected macrophages derived from human monocytes (MDMs) (61). In addition, coinfection with helminth significantly decreases the production of numerous CC and CXC chemokines in the individuals with latent TB infection, but anti-helminth treatment upregulated the chemokine responses in latent TB (62). These data suggest that either nicotine itself or coinfection with helminth negatively regulates the production of innate immune mediators that are needed for host protective defense against TB.

\section{Chemokines that enhance innate immunity during TB}

The specific chemokines and their receptors play critical roles in the enhancement of innate immune responses contributing to protective immunity against Mtb infection. Recent studies have reported that the anti-mycobacterial role of oligoadenylate synthetases (OASs) and OAS-like protein is at least partly mediated through induction of chemokine. Indeed, OAS proteins play critical roles in degradation of viruses to promote antiviral responses (63). It was shown that pathogenic Mtb infection enhances the expression of OAS-like (OASL) protein in human macrophage THP-1 cells. In addition, silencing OASL significantly increases intracellular Mtb growth and decreases the production of IL-1 $\beta$, TNF- $\alpha$, and MCP-1 in THP-1 cells. OASL-induced pro-inflammatory cytokines and chemokines may contribute to suppress intracellular Mtb survival (64). Moreover, 2',5'-oligoadenylate synthetases (OASs; OAS1, 2, and 3) contribute to antimicrobial host defense against intracellular pathogenic Mtb through enhancement of IL-1 $\beta$ and MCP-1 (65).

One way that Mtb drives a persistent infection is to inhibit inflammation through shifting macrophages as an immunoregulatory M2 phenotype. It is noted that Mtb effector Early Secreted Antigenic Target 6 kDa (ESAT-6) has an effect to switch macrophage differentiation into M2 phenotype, and downregulates cytokines IL- 6 and chemokines CXCL10 and CXCL1 (66). In contrast, other studies discovered that ESAT6, the virulence factor of Mtb, enhances the innate immunity of THP-1 macrophages, through production of various pro-inflammatory and anti-inflammatory cytokines and chemokines (67). The controversial results of ESAT-6 protein among these studies might be due to different cell conditions and multidrug-resistant strain of Mtb leads to inhibit CXCL8 and TNF- $\alpha$ production in bronchial epithelial cells, thereby affecting neutrophil effector functions (68). Thus downregulation of host chemokine responses during virulent Mtb infection may contribute to defective host defense through formation of a "silent" granuloma through inhibition of inflammation and/or impairment of neutrophil activities during Mtb infection. Taken together, these findings strongly suggest that the balanced secretion of chemokines are critical for the optimal induction of host defense during TB.

\section{Role of CXCR3 in protective immunity during TB}

Several studies emphasize the function of CXCR3 and ligand chemokines in the induction of host protective responses against TB. CXCR3, the CXCL9 and CXCL10 receptors, is induced and mainly expressed in type-1 helper (Th1)-type CD4(+) T cells, effector CD8(+) T cells and innate-type lymphocytes (40). In addition, Th1 cytokine IFN-r is able to drive CXCL9 and CXCL10 production in mononuclear phagocytes (40). In a non-human primate Mtb infection model, Mtb-specific effector 
T cells, such as IL-17+ and IL-17/IFN- $\gamma$ double-positive $T$ cells, are primarily found in the airways rather than periphery model. Additionally, these Mtb-specific CD4 T cells express the chemokine receptors CXCR3 and CCR6 and the population of CXCR3+CD4+ cells inversely correlated with Mtb burden. These data suggest that Mtb-specific $T$ cell responses are strongly associated with controlling Mtb infection in asymptomatic latent TB infection (69).

In an effort of vaccination study using Mycobacterium indicus pranii (MIP), a promising TB vaccine candidate, intranasal immunization with MIP significantly enhances the recruitment of CD4+ and CD8+ T-cells and induces a strong memory T-cell response in the lung airway lumen. Importantly, the MIP-mediated protective T-cells are mainly regulated by CXCR3-CXCL11 axis and exhibit protective immunity against Mtb infection (70). Putting together, CXCR3-CXCL11 axis is critically required for protective immune responses against Mtb but more studies are needed to clarify the chemokine signaling in terms of anti-TB vaccination.

A recent founding recommended the role for BATF3-dependent CD103+ dendritic cells (DCs) in protective Th1 immune responses to $M$. bovis BCG infection and Helicobacteri pylori infection would be crucial. Importantly, CXCR3 and its ligands CXCL9, 10, and 11 are required for the functional activation of BATF3-dependent CD103+ DCs in the expansion and recruitment of CXCR3+ effector and regulatory T cells for control of infection (71). Although the protective role of RANTES (CCL5) remains to be determined in pleural TB, low levels of CCL5 was associated with poor compartmentalization of antigen-specific T cells in the disease sites (72). Additionally, CXCR3+CCR4-CD4+T-cells from pleural fluid mononuclear cells play as multifunctional T-helper 1 cells; whereas CXCR3+CCR4+CD4+ T-cells upregulates cytotoxic functions, suggesting differential biological roles of chemokine receptors on CD4+ T cells during extrapulmonary TB infection (73). Together, these data strongly enhance the therapeutic function of specific chemokines particularly through the protective $T$ cell recruitment during TB infection.

\section{Protective roles of chemokines in terms of age and gender}

In infants, since they exhibit lower chemokines including CXCL9, TB infection is likely to develop as lethal disseminated forms than older aged persons and infant alveolar macrophages are less protective against Mtb, even though infant alveolar macrophages have similar ability of phagocytosis and immune phenotypes, as in those of adults (74).

One of the long-lasing questions among TB infections is its higher susceptibility of men than women. A recent study showed that the increased susceptibility of male mice towards Mtb infection with the Beijing strain HN878 was associated with defective lymphoid follicle formation in the lungs. The development of ectopic lymphoid structures requires homeostatic chemokines and inflammatory cytokines such as IL-23, CXCL13, and CCL19 and were significantly lower in male compared to lungs in female during infection (75). In addition, although more extended study should clarify the clinical meaning of IL-8 levels in TB, the cross-sectional study of TB patients in various stages and healthy controls presented that low levels of IL-8 are associated with poor outcome and relapse of TB (76). These studies recommend that the chemokine expression is required for immune homeostasis and prevention of disease progression during TB. However, understanding how the protective chemokine responses are regulated in short-term or long-term infection of TB remains unclear. In summary, the protective roles of chemokines during TB infection are listed in Table 2.

\section{DETRIMENTAL ROLES OF CHEMOKINES DURING TB INFECTION}

\section{Chemokines drive neutrophil infiltration to promote pathologic inflammation}

Although innate immune defense is critical in antimicrobial responses, uncontrolled activation of inflammatory responses is harmful to the host. A landmark study demonstrated detrimental function of hyperactivation of CXCL5 in TB through 
driving destructive neutrophilic inflammation (77). To support this finding, a con-current study indicated that SIRT3 deficiency led to detrimental effects against Mtb infection through excessive pathological inflammation including hyperactivation of CXCL5 in the lung tissues (78). Interestingly, TLR2 plays a host protective role in the controlling neutrophil-driven immmunopatholgical reaction during the infection with Mtb HN878, the W-Beijing strain (79).

Although several chemokine/chemokine receptor axis plays a critical role in the protection against Mtb infection as stated above, CXCR6 appears to be detrimental in host protection against Mtb infection (80). It was reported that CXCR6 deficiency inhibited in vivo bacterial burden in the mouse lungs after Mtb infection. CXCR6 deficiency leads to the increased recruitment of CD4+ T lymphocytes to the lungs during early infection and paradoxically reduce the Th1-cytokine response in the lung parenchyma (80). These data suggest that specific chemokine-chemokine receptor axis influences pathological inflammatory responses and affects host control of Mtb infection. Thus it would be important to dissect the role of chemokines and their receptors during acute and chronic stages of TB infection for future development of novel therapeutic strategies against TB.

Another recent study showed that the alarmin S100A8/A9 was found to be responsible for neutrophil accumulation during chronic TB infection. S100A8/A9 expression contributed to upregulation of the integrin CD11b on neutrophils to promote accumulation during TB. In addition, the patients with TB progression had an increased expression of S100A8 and S100A9 mRNAs and decreased S100A8/A9 protein levels in sera after anti-TB therapy (81). These data suggest that S100A8/A9 and chemokines works as markers of distinction between active pulmonary and latent TB subjects and therapeutic targets for host-directed therapy against TB.

\section{Chemokines to drive M2 phenotype to contribute to TB infection}

Mtb survival leading to latent infection is associated with differentiation of macrophage M2 phenotype. Mtb heat-shock protein 16.3 is greatly expressed during latent infection and responsible for driving into macrophage $M 2$ phenotype which depends on the chemokine receptors CCRL2 and CX3CR1 (82). In terms of M2 spectrum of macrophage activation, DC-SIGN (CD209/CLEC4L), a C-type lectin receptor (CLR), plays an important role in the negative regulation of pro-inflammatory cytokine/chemokine responses and plays dual roles in the increase of permission of bacterial survival and controlling pathological inflammation (83).

\section{Chemokine storms during TB co-infection with HIV and filarial infections}

In a prospective large cohort study in HIV-infected hospitalized patients who were newly diagnosed with HIV-associated TB, excessively increased immune profile including innate immune markers and chemotactic signaling (IL-1R antagonist [IL-1Ra], IL-6, IL-8, CCL4, CXCL10, CCL3) exhibited an association with TB dissemination and its high mortality (84). During filarial co-infected TB lymphadenitis, mycobacterial burden is significantly increased (85). Although IL-12 production is significantly decreased, the coinfection of filarial infection with extra-pulmonary TB leads to the elevation of numerous CC and CXC chemokines (85), suggesting that the elevated chemokines during filarial infections may provide pathogenic bystander effects upon tuberculous lymphadenitis. Taken together, the pathophysiological roles of inflammatory chemokines, derived from a high mycobacterial load in the co-infected patients are to promote pathogenic effects during TB co-infection with other pathogens. The detrimental roles of chemokines during TB infection are summarized in Table 3.

\section{CONCLUSION}

It is now clear that a variety of chemokines play multiple roles such as potential diagnosis, granuloma formation, protective immune defense, and pathological inflammation during TB infection. Numerous chemokines, in particular CXCL10, were advised potential biomarkers for pulmonary and extrapulmonary TB and LTBI. However, more evidence should be 
accumulated to clarify the potential usefulness of specific chemokine(s) in different types and stages of TB by designing an experiment with a larger sample size, different ethnic and geographic origins, and a comprehensively integrative analysis including genetics. A variety of chemokine-chemokine receptor axis such as CXCR5/CXCL1 and CXCR3/CXCL11 was reported as their protective roles in controlling Mtb infection. Recent studies have elucidated on the protective functions of the chemokine-chemokine receptor axis at the activation of adaptive immune responses during infection. Future studies are warranted to investigate how and which types of cells participate in the anti-mycobacterial host defense in terms of chemokine signaling. In contrast, chemokines also contribute to TB infection pathogenesis by enhancing uncontrolled inflammation, neutrophil infiltration, M2 macrophage differentiation, and etc. However, several fundamental questions still remain to be answered. How does co-infection of HIV and TB induce cytokine/chemokine storms during treatment? What are the genetic influences that lead to pathological inflammation due to hyperactivation of chemokines? Can the inhibitors of chemokine-chemokine receptor axis restore protective immune function at early and chronic Mtb infection? The answers for all of these questions and even another question will necessitate future comprehensive studies, including analysis of chemokine profiles for larger TB patient cohorts, experimental models, and genetic and immunological studies for chemokine functions during Mtb infection.

Table 1. Chemokines as biomarkers during TB infection

\begin{tabular}{|c|c|c|c|c|}
\hline Disease & Study model & Chemokine & Conclusion & Reference \\
\hline \multicolumn{5}{|c|}{ CXCL10/IP-10 as biomarkers in TB } \\
\hline PTB & $\begin{array}{c}\text { Meta-analysis } \\
\text { (18 studies, } 2836 \text { participants) }\end{array}$ & \multirow{4}{*}{ IP-10 } & $\begin{array}{l}\text { IP-10 is a promising marker for differentiating PTB } \\
\text { from non-TB. }\end{array}$ & $(41)$ \\
\hline LTBI & $\begin{array}{c}\text { Meta-analysis } \\
\text { (12 studies, } 1023 \text { participants) }\end{array}$ & & $\begin{array}{l}\text { IP-10 is a promising biomarker for the diagnosis of } \\
\text { LTBI. }\end{array}$ & $(42)$ \\
\hline ATB & $\begin{array}{l}\text { Observational study with ELISA } \\
\text { detection (95 ATB, } 52 \text { LTBI, and } 91 \mathrm{HC} \text { ) }\end{array}$ & & $\begin{array}{l}\text { Direct analysis of IP-10 may be applicable in } \\
\text { designing novel diagnostic tests for ATB. }\end{array}$ & (43) \\
\hline $\begin{array}{l}\text { PTB and } \\
\text { LTBI }\end{array}$ & $\begin{array}{l}\text { Observational study with ELISA } \\
\text { detection (30 ATB, } 29 \text { LTBI, and } 30 \mathrm{HC} \text { ) }\end{array}$ & & $\begin{array}{l}\text { IP-10 stimulated by recombinant PE } 35 \text { and PPE } 68 \text { is } \\
\text { a promising biomarker for TB diagnosis, but show } \\
\text { no sensitivity and specificity in distinguishing } \\
\text { between PTB and LTBI. }\end{array}$ & $(45)$ \\
\hline \multicolumn{5}{|c|}{ Other biomarkers in TB } \\
\hline TB & $\begin{array}{l}\text { Observational study with ELISA detection } \\
\text { (88 ATB, } 44 \text { LTBI, and } 44 \mathrm{HC})\end{array}$ & $\begin{array}{l}\mathrm{CCL1}, \mathrm{CCL} 3 \\
\mathrm{CXCL1} \\
\mathrm{CXCL9}, \text { and } \\
\text { CXCL10 }\end{array}$ & $\begin{array}{l}\text { Chemokines are markers of disease severity, } \\
\text { increased bacterial burden, and delayed culture } \\
\text { conversion in PTB. }\end{array}$ & (39) \\
\hline $\begin{array}{l}\text { ATB and } \\
\text { LTBI }\end{array}$ & $\begin{array}{l}\text { Observational study with ELISA detection } \\
\quad(97 \mathrm{ATB}, 113 \mathrm{LTBI} \text {, and } 101 \mathrm{HC})\end{array}$ & MCP-1 & $\begin{array}{l}\text { MCP-1 may be a potential clinical parameter for } \\
\text { distinguishing ATB from LTBI with high sensitivity } \\
\text { and specificity. }\end{array}$ & $(47)$ \\
\hline LTBI & $\begin{array}{l}\text { qPCR analysis from INH received } \mathrm{LTBI} \\
\text { patients }\end{array}$ & $\begin{array}{l}\text { CCL4 and } \\
\text { CXCL11 }\end{array}$ & $\begin{array}{l}\text { CCL4 and CXCL11 expressions during INH treatment } \\
\text { are potential tools for monitoring LTBI treatment. }\end{array}$ & (49) \\
\hline TB & $\begin{array}{c}\text { Meta-analysis } \\
\text { (9 studies, } 2584 \text { TB patients, } 2265 \mathrm{HC} \text { ) }\end{array}$ & CCL5 & $\begin{array}{l}\text { CCL5 rs } 2107538 \text { polymorphism might contribute } \\
\text { to the risk of TB, especially in Caucasians. }\end{array}$ & (50) \\
\hline \multicolumn{5}{|c|}{ Biomarkers in extrapulmonary TB } \\
\hline TPE & $\begin{array}{l}\text { Transcriptome sequencing of } \\
\text { PD-1-expressing MAIT cells }\end{array}$ & CXCL13 & $\begin{array}{l}\text { PD-1-expressing MAIT cells were associated with } \\
\text { extent of TB infections and production of CXCL13. }\end{array}$ & $(52)$ \\
\hline TPE & $\begin{array}{l}\text { Chemokine arrays, cytokine measurements, } \\
\text { and flow cytometry analysis }\end{array}$ & CCL27 & $\begin{array}{l}\text { Pleural fluid CCL27 may help in diagnosing TPE in } \\
\text { patients with moderate elevation of pleural fluid } \\
\text { ADA levels. }\end{array}$ & (55) \\
\hline TBM & $\begin{array}{l}\text { Cytokine profile of mononuclear cells } \\
\text { isolated from CSF and PBMCs }\end{array}$ & MIP-1 $\alpha$ & $\begin{array}{l}\text { CSF MIP-1 } \alpha \text { concentrations appear to be useful } \\
\text { adjuncts for diagnosing TBM. }\end{array}$ & (56) \\
\hline
\end{tabular}

PTB, pulmonary tuberculosis; IP-10, interferon- $\gamma$-induced protein 10; LTBI, latent tuberculosis infection; ELISA, enzyme-linked immunosorbent assay; ATB, active tuberculosis; HC, healthy control; MCP-1, monocyte chemoattractant protein-1; TPE, tuberculosis pleural effusion; PD-1, programmed death protein 1; PBMC, peripheral blood mononuclear cells; MAIT cells, mucosalassociated invariant T cells; ADA, adenosine deaminase; TBM, tuberculous meningitis; CSF, cerebrospinal fluid 
Table 2. Protective roles of chemokines during TB infection

\begin{tabular}{|c|c|c|c|c|}
\hline $\begin{array}{l}\text { Disease or } \\
\text { pathogen }\end{array}$ & Study model & $\begin{array}{l}\text { Chemokine and/or } \\
\text { chemokine receptor }\end{array}$ & Conclusion & Reference \\
\hline \multicolumn{5}{|c|}{ Activation of protective T cells and innate lymphoid cells } \\
\hline H37Rv & $\begin{array}{l}\text { CD4 T cells isolated from } \\
\text { lungs of Mtb-infected mice }\end{array}$ & $\begin{array}{l}\text { CXCR3, CXCR6, } \\
\text { CCR2, and CCR5 (and } \\
\text { CCR6 in humans) }\end{array}$ & $\begin{array}{l}\text { Mtb-specific effector CD4 T cells that co-express } \\
\text { multiple chemokine receptors may be the best } \\
\text { lung-homing CD4 T cells. }\end{array}$ & (57) \\
\hline $\begin{array}{l}\text { PTB and } \\
\text { H37Rv }\end{array}$ & $\begin{array}{l}\text { ILCs from PTB patients and } \\
\text { Mtb-infected mice }\end{array}$ & CXCR5/CXCL13 & $\begin{array}{l}\text { CXCR5/CXCL13 is required for the protective } \\
\text { immunity against Mtb infection through functional } \\
\text { activation of ILC3s during Mtb infection. }\end{array}$ & (59) \\
\hline H37Rv & MDMs & CXCL9 and CXCL10 & $\begin{array}{l}\text { Nicotine negatively regulates the production of } \\
\text { innate immune mediators necessary for the host } \\
\text { defense against TB. }\end{array}$ & (61) \\
\hline $\begin{array}{l}\text { Helminth } \\
\text { coinfection } \\
\text { with LTBI }\end{array}$ & $\begin{array}{l}\text { Whole blood from } 120 \\
\text { individuals ( } 40 \text { coinfection, } \\
40 \text { LTBI, and } 30 \mathrm{HC} \text { ) }\end{array}$ & $\begin{array}{l}\text { CCL1, CCL2, CCL4, } \\
\text { CCL11, CXCL9, } \\
\text { CXCL10 and CXCL11 }\end{array}$ & $\begin{array}{l}\text { Coexistent helminth infection induces down } \\
\text { regulation of chemokine responses in LTBI patients. }\end{array}$ & (62) \\
\hline \multicolumn{5}{|c|}{ Enhancement of innate immunity } \\
\hline $\begin{array}{l}\text { Mtb Beijing } \\
\text { strain and } \\
\text { BCG }\end{array}$ & THP-1 cells & MCP-1 & $\begin{array}{l}\text { OASs and OAS-like protein suppress intracellular } \\
\text { Mtb survival through enhancement of IL-1 } 1 \beta \text { and } \\
\text { MCP-1. }\end{array}$ & $\begin{array}{l}(64) \\
(65)\end{array}$ \\
\hline $\begin{array}{l}\text { Mtb virulent } \\
\text { factor } \\
\text { ESAT- } 6\end{array}$ & PBMCs & CXCL10 and CXCL1 & $\begin{array}{l}\text { ESAT- } 6 \text { switch macrophage differentiation into M2 } \\
\text { pheynotype, and downregulates chemokines } \\
\text { CXCL10 and CXCL1. }\end{array}$ & (66) \\
\hline $\begin{array}{l}\text { MDR Mtb } \\
\text { strain M }\end{array}$ & $\begin{array}{l}\text { Bronchial epithelial cell } \\
\quad \text { line Calu-6 }\end{array}$ & CXCL8 & $\begin{array}{l}\text { MDR strain of Mtb inhibit CXCL8 production in } \\
\text { bronchial epithelial cells, affecting neutrophil } \\
\text { effector functions. }\end{array}$ & (68) \\
\hline \multicolumn{5}{|c|}{ Roles of CXCR3 } \\
\hline $\begin{array}{l}\text { Mtb } \\
\text { CDC1551 }\end{array}$ & $\begin{array}{l}\text { T cells isolated from lungs } \\
\text { of Mtb-infected rhesus } \\
\text { macaques }\end{array}$ & CXCR3 and CCR6 & $\begin{array}{l}\text { Mtb-specific T cells expressed the chemokine } \\
\text { receptors CXCR3 and CCR6, which inversely } \\
\text { correlated with Mtb burden. }\end{array}$ & (69) \\
\hline $\begin{array}{l}\text { H37Rv and } \\
\text { MIP }\end{array}$ & $\begin{array}{l}\text { BAL cells from } \\
\text { MIP-immunized } \\
\text { Mtb-infected mice }\end{array}$ & CXCR3-CXCL11 axis & $\begin{array}{l}\text { MIP-mediated protective T-cells were mainly } \\
\text { regulated by CXCR3-CXCL11 axis, which exhibited } \\
\text { protective immunity against Mtb infection }\end{array}$ & (70) \\
\hline $\begin{array}{l}\text { BCG and } \\
\text { H. pylori }\end{array}$ & $\begin{array}{l}\text { BATF3-dependent DCs } \\
\text { from infected mice }\end{array}$ & $\begin{array}{l}\text { CXCR3 and its ligands } \\
\text { CXCL9, 10, and } 11\end{array}$ & $\begin{array}{l}\text { M. bovis BCG infection strongly reduced } \\
\text { production of the chemokines and CXCR3 ligands } \\
\text { in BATF3-deficient mice }\end{array}$ & (71) \\
\hline TPE & $\begin{array}{l}\text { PFMCs, PBMCs, and } \\
\text { CBMCs }\end{array}$ & CXCR3 and CCR4 & $\begin{array}{l}\text { CXCR3 or CCR4 expression on CD4+ T-cells had } \\
\text { different biological activities against Mtb infection, and } \\
\text { could be a potential marker for the diagnosis of TB. }\end{array}$ & (73) \\
\hline \multicolumn{5}{|c|}{ Protective roles of chemokines in terms of age and gender } \\
\hline H37Rv & $\begin{array}{l}\text { Alveolar macrophages } \\
\text { from human BAL fluids }\end{array}$ & CXCL9 & $\begin{array}{l}\text { Infant alveolar macrophages are less protective } \\
\text { against Mtb, since they exhibit lower chemokines } \\
\text { such as CXCL9. }\end{array}$ & (74) \\
\hline $\begin{array}{l}\text { Mtb Beijing } \\
\text { strain HN878 } \\
\text { and H37Rv }\end{array}$ & $\begin{array}{l}\text { Lung cells from } \\
\text { Mtb-infected mice }\end{array}$ & CXCL13 and CCL19 & $\begin{array}{l}\text { Homeostatic chemokines CXCL13 and CCL19 were } \\
\text { significantly lower in male compared to female } \\
\text { lungs, during infection. }\end{array}$ & (75) \\
\hline $\begin{array}{l}\text { TB and TB } \\
\text { relapse }\end{array}$ & $\begin{array}{l}\text { Cross-sectional study } \\
\text { (TB, TB relapse, anti-TB } \\
\text { treated, and } \mathrm{HC} \text { ) }\end{array}$ & CXCL8 & $\begin{array}{l}\text { Low levels of CXCL8 were associated with poor } \\
\text { outcome and relapse of TB. }\end{array}$ & (76) \\
\hline
\end{tabular}

PTB, pulmonary tuberculosis; ILCs, innate lymphoid cells; MDMs, macrophages derived from human monocytes; OAS, oligoadenylate synthetase; ESAT-6, early secreted antigenic target $6 \mathrm{kDa}$; PBMCs, peripheral blood human mononuclear cells; MDR, multi-drug resistant; BAL, bronchoalveolar lavage; MIP, Mycobacterium indicus pranii; H. pylori, Helicobacter pylori, DCs, dendritic cells; TPE, tuberculous pleural effusion; PFMCs, pleural fluid mononuclear cells; CBMCs, cord blood mononuclear cells 
Table 3. Detrimental roles of chemokines during TB infection

\begin{tabular}{|c|c|c|c|c|}
\hline $\begin{array}{l}\text { Disease or } \\
\text { pathogen }\end{array}$ & Study model & $\begin{array}{l}\text { Chemokine and/or } \\
\text { chemokine receptor }\end{array}$ & Conclusion & Reference \\
\hline \multicolumn{5}{|c|}{ Chemokines drive neutrophil infiltration to promote pathologic inflammation } \\
\hline H37Rv & $\begin{array}{l}\text { in vivo mice aerosol } \\
\text { infection }\end{array}$ & CXCL5 & $\begin{array}{l}\text { TLR2-induced epithelial-derived CXCL5 was } \\
\text { critical for PMN-driven destructive } \\
\text { inflammation in PTB. }\end{array}$ & (77) \\
\hline $\begin{array}{l}\text { H37Rv and } \\
\text { BCG }\end{array}$ & $\begin{array}{l}\text { in vivo mice intranasal } \\
\text { infection / human PBMCs } \\
\text { and MDMs }\end{array}$ & CXCL5 & $\begin{array}{l}\text { SIRT3 deficiency led to excessive pathological } \\
\text { inflammation including hyperactivation of } \\
\text { CXCL5 in the lung tissues. }\end{array}$ & (78) \\
\hline HN878 & $\begin{array}{l}\text { in vivo mice aerosol } \\
\text { infection }\end{array}$ & CXCL5 & $\begin{array}{l}\text { TLR2 controlled neutrophil-driven } \\
\text { immunopathology during Mtb HN878 } \\
\text { infection by curtailing CXCL5 production. }\end{array}$ & (79) \\
\hline H37Rv & $\begin{array}{l}\text { in vivo mice aerosol } \\
\text { infection }\end{array}$ & CXCR6 & $\begin{array}{l}\text { CXCR6 deficiency resulted in reduced bacterial } \\
\text { burden after Mtb infection. }\end{array}$ & $(80)$ \\
\hline H37Rv / ATB & $\begin{array}{l}\text { in vivo mice aerosol } \\
\text { infection / ATB cohort }\end{array}$ & CXCL1 and CXCL10 & $\begin{array}{l}\text { Combining S100A8/A9 along with CXCL1 and } \\
\text { CXCL10 into a biomarker signature improved } \\
\text { differentiation between ATB and HCS. }\end{array}$ & $(81)$ \\
\hline \multicolumn{5}{|c|}{ Chemokines to drive M2 phenotype to contribute to TB infection } \\
\hline Mtb HSP16.3 & $\begin{array}{l}\text { BMDMs differentiated } \\
\text { from BALB/C mice }\end{array}$ & CCRL2 and CX3CR1 & $\begin{array}{l}\text { Mtb Hsp16.3 promoted macrophages to M2 } \\
\text { phenotype, which depended on the } \\
\text { chemokine receptors CCRL2 and CX3CR1. }\end{array}$ & $(82)$ \\
\hline H37Rv /TB & $\begin{array}{l}\text { Rhesus macaques / } \\
\text { Human MDMs from TB } \\
\text { patients and HC }\end{array}$ & $\mathrm{CXCL1}$ & $\begin{array}{l}\text { DC-SIGN negatively regulated the } \\
\text { pro-inflammatory cytokine/ chemokine } \\
\text { responses in terms of } \mathrm{M} 2 \text { spectrum of } \\
\text { macrophages under } \mathrm{Mtb} \text { infection }\end{array}$ & (83) \\
\hline \multicolumn{5}{|c|}{ Chemokine storms during TB co-infection with HIV and filarial infections } \\
\hline $\begin{array}{l}\text { HIV-associate } \\
\quad \text { d TB }\end{array}$ & $\begin{array}{l}\text { Prospective large cohort } \\
\text { study }\end{array}$ & CCL4, CXCL10, CCL3 & $\begin{array}{l}\text { Immune profile of HIV-associated TB patients } \\
\text { was associated with both tuberculosis } \\
\text { dissemination and mortality. }\end{array}$ & (84) \\
\hline $\begin{array}{l}\text { Filarial } \\
\text { co-infected } \\
\text { TBL }\end{array}$ & $\begin{array}{l}\text { TBL and filarial-TBL } \\
\text { co-infected patients }\end{array}$ & $\begin{array}{l}\text { CCs (CCL1, CCL2, CCL11) } \\
\text { and } C X C s(C X C L 2, C X C L 8, \\
\quad \text { CXCL9, CXCL11) }\end{array}$ & $\begin{array}{l}\text { Numerous CC and CXC chemokines were } \\
\text { clearly elevated in filarial-TBL co-infection, } \\
\text { suggesting potential pathogenic role in TBL. }\end{array}$ & $(85)$ \\
\hline
\end{tabular}

TLR, toll-like receptor; PMN, polymorphonuclear leukocytes; PTB, pulmonary tuberculosis; BCG, Bacillus Calmette-Guérin; TLR; HSP, heat-shock protein; BMDM, bone marrow-derived macrophage; MDMs, monocyte-derived macrophages; HC, healthy control; DC-SIGN, dendritic cell-specific intercellular adhesion molecule-3-grabbing non-integrin; TBL, tuberculosis lymphadenitis

\section{ACKNOWLEDGEMENTS}

This work was supported by research fund of Chungnam National University. We are indebted to current members of Prof. Jo's Lab for discussions and investigations that contributed to this article. We apologize to colleagues whose work and publications could not be referenced owing to space constraints.

\section{DISCLOSURE OF POTENTIAL CONFLICT OF INTEREST}

The authors declare no competing financial interests. 


\section{REFERENCES}

1) Chaw L, Chien LC, Wong J, Takahashi K, Koh D, Lin RT. Global trends and gaps in research related to latent tuberculosis infection. BMC Public Health 2020;20:352.

2) Dheda K, Gumbo T, Maartens G, Dooley KE, McNerney R, Murray M, et al. The epidemiology, pathogenesis, transmission, diagnosis, and management of multidrug-resistant, extensively drug-resistant, and incurable tuberculosis. Lancet Respir Med 2017:S2213-2600(17)30079-6.

3) Herrera M, Vera C, Keynan Y, Rueda ZV. Gaps in Study Design for Immune Parameter Research for Latent Tuberculosis Infection: A Systematic Review. J Immunol Res 2020;2020:8074183.

4) Yong YK, Tan HY, Saeidi A, Wong WF, Vignesh R, Velu V, et al. Immune Biomarkers for Diagnosis and Treatment Monitoring of Tuberculosis: Current Developments and Future Prospects. Front Microbio/2019;10:2789.

5) Barry CE 3rd, Boshoff HI, Dartois V, Dick T, Ehrt S, Flynn J, et al. The spectrum of latent tuberculosis: rethinking the biology and intervention strategies. Nat Rev Microbio/2009;7:845-55.

6) Sommer F, Torraca V, Meijer AH. Chemokine Receptors and Phagocyte Biology in Zebrafish. Front Immunol 2020:11:325.

7) Mukai K, Tsai M, Saito H, Galli SJ. Mast cells as sources of cytokines, chemokines, and growth factors. Immunol Rev 2018:282:121-50

8) Domingo-Gonzalez R, Prince O, Cooper A, Khader SA. Cytokines and Chemokines in Mycobacterium tuberculosis Infection. Microbio/ Spectr 2016;4:TBTB2-0018-2016.

9) Monin L, Khader SA. Chemokines in tuberculosis: the good, the bad and the ugly. Semin Immuno/2014;26:552-8.

10) Torraca V, Tulotta $C$, Snaar-Jagalska BE, Meijer AH. The chemokine receptor CXCR4 promotes granuloma formation by sustaining a mycobacteria-induced angiogenesis programme. Sci Rep 2017:7:45061.

11) Cooper AM, Mayer-Barber KD, Sher A. Role of innate cytokines in mycobacterial infection. Mucosal Immunol 2011:4:252-60.

12) Daley CL, Caminero JA. Management of multidrug resistant tuberculosis. Semin Respir Crit Care Med 2013;34:44-59.

13) de Martino M, Lodi L, Galli L, Chiappini E. Immune Response to Mycobacterium tuberculosis: A Narrative Review. Front Pediatr 2019:7:350.

14) Bruyn ED, Wilkinson RJ. The Immune Interaction between HIV-1 Infection and Mycobacterium tuberculosis. Microbiol Spectr 2016;4:TBTB2-0012-2016.

15) Shim D, Kim H, Shin SJ. Mycobacterium tuberculosis Infection-Driven Foamy Macrophages and Their Implications in Tuberculosis Control as Targets for Host-Directed Therapy. Front Immuno/ 2020;11:910.

16) Sharan R, Bucsan AN, Ganatra S, Paiardini M, Mohan M, Mehra S, et al. Chronic Immune Activation in TB/HIV Co-infection. Trends Microbio/2020;28:619-32.

17) Shankar EM, Vignesh R, Ellegård R, Barathan M, Chong YK, Bador MK, et al. HIV-Mycobacterium tuberculosis co-infection: a 'danger-couple model' of disease pathogenesis. Pathog Dis 2014;70:110-8.

18) Lai RPJ, Meintjes G, Wilkinson RJ. HIV-1 tuberculosis-associated immune reconstitution inflammatory syndrome. Semin Immunopatho/ 2016:38:185-98. 
19) Hunter RL. Tuberculosis as a three-act play: A new paradigm for the pathogenesis of pulmonary tuberculosis. Tuberculosis (Edinb) 2016:97:8-17.

20) Roach DR, Bean AGD, Demangel C, France MP, Briscoe H, Britton WJ. TNF regulates chemokine induction essential for cell recruitment, granuloma formation, and clearance of mycobacterial infection. J Immuno/2002:168:4620-7.

21) Turner RD, Chiu C, Churchyard GJ, Esmail H, Lewinsohn DM, Gandhi NR, et al. Tuberculosis Infectiousness and Host Susceptibility. J Infect Dis 2017;216:S636-S43.

22) Wang MG, Luo L, Zhang Y, Liu X, Liu L, He JQ. Treatment outcomes of tuberculous meningitis in adults: a systematic review and meta-analysis. BMC Pulm Med 2019;19:200.

23) Zhai K, Lu Y, Shi HZ. Tuberculous pleural effusion. J Thorac Dis 2016:8:E486-94.

24) Cho JK, Choi YM, Lee SS, Park HK, Cha RR, Kim WS, et al. Clinical features and outcomes of abdominal tuberculosis in southeastern Korea: 12 years of experience. BMC Infect Dis 2018;18:699.

25) Zajaczkowski T. Genitourinary tuberculosis: historical and basic science review: past and present. Cent European J Uro/2012:65:182-7.

26) Tong ZH, Shi HZ. Subpopulations of helper T lymphocytes in tuberculous pleurisy. Tuberculosis (Edinb) 2013:93:279-84.

27) Guerreiro R, Santos-Costa Q, Azevedo-Pereira JM. [The chemokines and their receptors: characteristics and physiological functions]. Acta Med Port 2011;24 Suppl 4:967-76.

28) Nagarsheth N, Wicha MS, Zou W. Chemokines in the cancer microenvironment and their relevance in cancer immunotherapy. Nat Rev Immuno/ 2017;17:559-72.

29) Marchese A. Endocytic trafficking of chemokine receptors. Curr Opin Cell Bio/2014;27:72-7.

30) Reyes ME, de La Fuente M, Hermoso M, Ili CG, Brebi P. Role of CC Chemokines Subfamily in the Platinum Drugs Resistance Promotion in Cancer. Front Immuno/2020;11:901.

31) Tripathi DK, Poluri KM. Molecular insights into kinase mediated signaling pathways of chemokines and their cognate G protein coupled receptors. Front Biosci (Landmark Ed) 2020;25:1361-85.

32) Hembruff SL, Cheng N. Chemokine signaling in cancer: Implications on the tumor microenvironment and therapeutic targeting. Cancer Ther 2009:7:254-67.

33) Saunders BM, Cooper AM. Restraining mycobacteria: role of granulomas in mycobacterial infections. Immuno/ Cell Biol2000;78:334-41.

34) Orme IM, Cooper AM. Cytokine/chemokine cascades in immunity to tuberculosis. Immuno/ Today 1999;20:307-12.

35) Wickremasinghe MI, Thomas LH, Friedland JS. Pulmonary epithelial cells are a source of IL-8 in the response to Mycobacterium tuberculosis: essential role of IL-1 from infected monocytes in a NF-kappa B-dependent network. J Immunol 1999;163:3936-47.

36) O'Kane CM, Boyle JJ, Horncastle DE, Elkington PT, Friedland JS. Monocyte-dependent fibroblast CXCL8 secretion occurs in tuberculosis and limits survival of mycobacteria within macrophages. J Immuno/2007;178:3767-76

37) Etna MP, Giacomini E, Severa M, Coccia EM. Pro- and anti-inflammatory cytokines in tuberculosis: a two-edged sword in TB pathogenesis. Semin Immuno/2014;26:543-51.

38) Orme IM, Henao-Tamayo MI. Trying to See the Forest through the Trees: Deciphering the Nature of Memory Immunity to Mycobacterium tuberculosis. Front Immuno/2018:9:461. 
39) Kumar NP, Moideen K, Nancy A, Viswanathan V, Shruthi BS, Sivakumar S, et al. Plasma chemokines are biomarkers of disease severity, higher bacterial burden and delayed sputum culture conversion in pulmonary tuberculosis. $S c i$ Rep 2019;9:18217.

40) Groom JR, Luster AD. CXCR3 ligands: redundant, collaborative and antagonistic functions. Immuno/ Cell Biol 2011:89:207-15.

41) Qiu X, Xiong T, Su X, Qu Y, Ge L, Yue Y, et al. Accumulate evidence for IP-10 in diagnosing pulmonary tuberculosis. BMC Infect Dis 2019;19:924.

42) Qiu X, Tang Y, Yue Y, Zeng Y, Li W, Qu Y, et al. Accuracy of interferon-gamma-induced protein 10 for diagnosing latent tuberculosis infection: a systematic review and meta-analysis. Clin Microbiol Infect 2019;25:667-72.

43) Wawrocki S, Seweryn M, Kielnierowski G, Rudnicka W, Wlodarczyk M, Druszczynska M. IL-18/IL-37/IP-10 signalling complex as a potential biomarker for discriminating active and latent TB. PLoS One 2019;14:e0225556.

44) Palmer MV, Thacker TC, Rabideau MM, Jones GJ, Kanipe C, Vordermeier HM, et al. Biomarkers of cell-mediated immunity to bovine tuberculosis. Vet Immunol Immunopatho/2020;220:109988.

45) Mamishi S, Mahmoudi S, Banar M, Hosseinpour Sadeghi R, Marjani M, Pourakbari B. Diagnostic accuracy of interferon (IFN)-gamma inducible protein 10 (IP-10) as a biomarker for the discrimination of active and latent tuberculosis. Mol Biol Rep 2019;46:6263-9.

46) Zhang W. IP-10 for the diagnosis of tuberculosis in children: Protocol for a systematic review and meta-analysis. Medicine (Baltimore) 2019;98:e15977.

47) Sun $T$, Wu B, Wang J, Yuan $T$, Huang $H, X u ~ D$, et al. Evaluation of the Diagnostic Efficacy of Monocyte Parameters and MCP-1 to Distinguishing Active Tuberculosis from Latent Tuberculosis. Clin Lab 2019;65.

48) Kathamuthu GR, Sridhar R, Baskaran D, Babu S. Low body mass index has minimal impact on plasma levels of cytokines and chemokines in tuberculous lymphadenitis. J Clin Tuberc Other Mycobact Dis 2020;20:100163.

49) de Oyarzabal E, García-García L, Rangel-Escareño C, Ferreyra-Reyes L, Orozco L, Herrera MT, et al. Expression of USP18 and IL2RA Is Increased in Individuals Receiving Latent Tuberculosis Treatment with Isoniazid. J Immunol Res 2019:2019:1297131.

50) Sheng YF, Qi Q. Association of chemotactic chemokine ligand 5 rs2107538 polymorphism with tuberculosis susceptibility: A meta-analysis. Innate Immun 2020;26:358-63.

51) Zhang M, Li D, Hu ZD, Huang YL. The diagnostic utility of pleural markers for tuberculosis pleural effusion. Ann Trans/ Med 2020;8:607.

52) Jiang J, Cao Z, Qu J, Liu H, Han H, Cheng X. PD-1-expressing MAIT cells from patients with tuberculosis exhibit elevated production of CXCL13. Scand J Immuno/2020;91:e12858.

53) Rao DA. T Cells That Help B Cells in Chronically Inflamed Tissues. Front Immuno/2018;9:1924.

54) Crotty S. T Follicular Helper Cell Biology: A Decade of Discovery and Diseases. Immunity 2019;50:1132-48.

55) Kim HJ, Ryu S, Choi SH, Seo H, Yoo SS, Lee SY, et al. Comparison of biochemical parameters and chemokine levels in pleural fluid between patients with anergic and non-anergic tuberculous pleural effusion. Tuberculosis (Edinb) 2020;123:101940.

56) Kwon JS, Park JH, Kim JY, Cha HH, Kim MJ, Chong YP, et al. Diagnostic Usefulness of Cytokine and Chemokine Levels in the Cerebrospinal Fluid of Patients with Suspected Tuberculous Meningitis. Am J Trop Med Hyg 2019;101:343-9. 
57) Hoft SG, Sallin MA, Kauffman KD, Sakai S, Ganusov VV, Barber DL. The Rate of CD4 T Cell Entry into the Lungs during Mycobacterium tuberculosis Infection Is Determined by Partial and Opposing Effects of Multiple Chemokine Receptors. Infect Immun 2019;87:e00841-18.

58) Sakai S, Kauffman KD, Schenkel JM, McBerry CC, Mayer-Barber KD, Masopust D, et al. Cutting edge: control of Mycobacterium tuberculosis infection by a subset of lung parenchyma-homing CD4 T cells. J Immuno/2014;192:2965-9

59) Ardain A, Domingo-Gonzalez R, Das S, Kazer SW, Howard NC, Singh A, et al. Group 3 innate lymphoid cells mediate early protective immunity against tuberculosis. Nature 2019;570:528-32

60) Matsuzaki G, Yamasaki M, Tamura T, Umemura M. Dispensable role of chemokine receptors in migration of mycobacterial antigen-specific CD4(+) T cells into Mycobacterium-infected lung. Immunobiology 2019;224:440-48

61) Valdez-Miramontes CE, Trejo Martínez LA, Torres-Juárez F, Rodríguez Carlos A, Marin-Luévano SP, de Haro-Acosta $J$, et al. Nicotine modulates molecules of the innate immune response in epithelial cells and macrophages during infection with M. tuberculosis. Clin Exp Immuno/2020;199:230-43

62) Rajamanickam A, Munisankar S, Bhootra Y, Dolla CK, Nutman TB, Babu S. Coexistent Helminth Infection-Mediated Modulation of Chemokine Responses in Latent Tuberculosis. J Immuno/2019;202:1494-500.

63) Choi UY, Kang JS, Hwang YS, Kim YJ. Oligoadenylate synthase-like (OASL) proteins: dual functions and associations with diseases. Exp MolMed 2015;47:e144.

64) Leisching G, Ali A, Cole V, Baker B. 2'-5'-Oligoadenylate synthetase-like protein inhibits intracellular M. tuberculosis replication and promotes proinflammatory cytokine secretion. Mol Immuno/2020;118:73-8.

65) Leisching G, Cole V, Ali AT, Baker B. OAS1, OAS2 and OAS3 restrict intracellular M. tb replication and enhance cytokine secretion. Int J Infect Dis 2019;80S:S77-S84.

66) Refai A, Gritli S, Barbouche MR, Essafi M. Mycobacterium tuberculosis Virulent Factor ESAT-6 Drives Macrophage Differentiation Toward the Pro-inflammatory M1 Phenotype and Subsequently Switches It to the Anti-inflammatory M2 Phenotype. Front Cell Infect Microbio/2018;8:327.

67) Li F, Luo J, Xu H, Wang Y, Jiang W, Chang K, et al. Early secreted antigenic target 6-kDa from Mycobacterium tuberculosis enhanced the protective innate immunity of macrophages partially via HIF1alpha. Biochem Biophys Res Commun 2020;522:26-32.

68) Kviatcovsky D, Rivadeneyra L, Balboa L, Yokobori N, López B, Ritacco V, et al. Mycobacterium tuberculosis Multidrug-Resistant Strain M Induces Low IL-8 and Inhibits TNF-alpha Secretion by Bronchial Epithelial Cells Altering Neutrophil Effector Functions. Mediators Inflamm 2017;2017:2810606.

69) Shanmugasundaram U, Bucsan AN, Ganatra SR, Ibegbu C, Quezada M, Blair RV, et al. Pulmonary Mycobacterium tuberculosis control associates with CXCR3- and CCR6-expressing antigen-specific Th1 and Th17 cell recruitment. JCI Insight 2020; 5:e137858.

70) Gupta A, Saqib M, Singh B, Pal L, Nishikanta A, Bhaskar S. Mycobacterium indicus pranii Induced Memory T-Cells in Lung Airways Are Sentinels for Improved Protection Against M.tb Infection. Front Immuno/2019;10:2359.

71) Arnold IC, Zhang $X$, Artola-Boran $M$, Fallegger A, Sander $P$, Johansen $P$, et al. BATF3-dependent dendritic cells drive both effector and regulatory T-cell responses in bacterially infected tissues. PLoS Pathog 2019;15:e1007866.

72) Pydi SS, Ghousunnissa S, Devalraju KP, Ramaseri SS, Gaddam R, Auzumeedi SK, et al. Down regulation of RANTES in pleural site is associated with inhibition of antigen specific response in tuberculosis. Tuberculosis (Edinb) 2019;116S:S123-S30. 
73) Yu S, Shen J, Lao S, Yang B, Wu C. Distinct functions of CXCR3(+) and CCR4(+)CD4(+) T-cells accumulated in human tuberculosis pleural fluid. Int J Tuberc Lung Dis 2018;22:1514-22.

74) Goenka A, Prise IE, Connolly E, Fernandez-Soto P, Morgan D, Cavet JS, et al. Infant Alveolar Macrophages Are Unable to Effectively Contain Mycobacterium tuberculosis. Front Immuno/2020;11:486.

75) Hertz D, Dibbern J, Eggers L, von Borstel L, Schneider BE. Increased male susceptibility to Mycobacterium tuberculosis infection is associated with smaller B cell follicles in the lungs. Sci Rep 2020;10:5142.

76) Waghmare PJ, Lende T, Goswami K, Gupta A, Gupta A, Gangane N, et al. Immunological host responses as surveillance and prognostic markers in tubercular infections. Int J Mycobacterio/2019:8:190-5.

77) Nouailles G, Dorhoi A, Koch M, Zerrahn J, Weiner J 3rd, Faé KC, et al. CXCL5-secreting pulmonary epithelial cells drive destructive neutrophilic inflammation in tuberculosis. J Clin Invest 2014;124:1268-82.

78) Kim TS, Jin YB, Kim YS, Kim S, Kim JK, Lee HM, et al. SIRT3 promotes antimycobacterial defenses by coordinating mitochondrial and autophagic functions. Autophagy 2019;15:1356-75.

79) Gopalakrishnan A, Dietzold J, Verma S, Bhagavathula M, Salgame P. Toll-like Receptor 2 Prevents Neutrophil-Driven Immunopathology during Infection with Mycobacterium tuberculosis by Curtailing CXCL5 Production. Infect Immun 2019; 87:e00760-18.

80) Ashhurst AS, Flórido M, Lin LCW, Quan D, Armitage E, Stifter SA, et al. CXCR6-Deficiency Improves the Control of Pulmonary Mycobacterium tuberculosis and Influenza Infection Independent of T-Lymphocyte Recruitment to the Lungs. Front Immuno/ 2019:10:339.

81) Scott NR, Swanson RV, Al-Hammadi N, Domingo-Gonzalez R, Rangel-Moreno J, Kriel BA, et al. S100A8/A9 regulates CD11b expression and neutrophil recruitment during chronic tuberculosis. J Clin Invest 2020;130:3098-112.

82) Zhang Y, Li S, Liu Q, Long R, Feng J, Qin H, et al. Mycobacterium tuberculosis Heat-Shock Protein 16.3 Induces Macrophage M2 Polarization Through CCRL2/CX3CR1. Inflammation 2020:43:487-506.

83) Lugo-Villarino G, Troegeler A, Balboa L, Lastrucci C, Duval C, Mercier I, et al. The C-Type Lectin Receptor DC-SIGN Has an Anti-Inflammatory Role in Human M(IL-4) Macrophages in Response to Mycobacterium tuberculosis. Front Immuno/2018;9:1123.

84) Schutz C, Barr D, Andrade BB, Shey M, Ward A, Janssen S, et al. Clinical, microbiologic, and immunologic determinants of mortality in hospitalized patients with HIV-associated tuberculosis: A prospective cohort study. PLOS Med 2019;16:e1002840.

85) Kathamuthu GR, Munisankar S, Banurekha VV, Nair D, Sridhar R, Babu S. Filarial Coinfection Is Associated With Higher Bacterial Burdens and Altered Plasma Cytokine and Chemokine Responses in Tuberculous Lymphadenitis. Front Immuno/2020;11:706. 